potent, but more transitory than that of deoxycorticosterone. Sodium retention requires only a moderate degree of potency; but a certain hormone-level must be maintained without interruption throughout the day. This may be accomplished by one injection per day of the slow-acting deoxycorticosterone, or by frequent injections of the quick-acting compound $E$, the daily doses being equal in both cases.

Physiological Laboratory,

H. WIRZ

University of Basle. Oct. 20.

${ }^{1}$ Kendall, E. C., J. Amer. Med. Assoc., 116, 2394 (1941).

2 Thorn, G. W., Engel, J. I., and Lewis, R. A., Science, 94. 348 (1941),

$s$ Verzár, F., Schuseiz. med. Wschr., 80, 468 (1950).

- Verzár, F., and Wang, F. C., Amer.J. Physiol., 159, 263 (1949); Nature, 165,114 (1950).

${ }^{5}$ Wirz, H., Helv. Physiol. Acta, 8, 186 (1950).

\section{Effects of the Thyroid, Castration and Season on Adrenals in the Male Rabbit}

WHILE studying the role of the thyroid on body growth $^{1}$ and sexual development ${ }^{2}$ in the young male rabbit, it was decided to observe the effects of known levels of thyroidal stimulation and inhibition on the adrenals, because they appear to be linked up with that part of the complex endocrine system which influences the various reproductive processes in the male. As castration and summer season both cause a decrease in the rate of secretion of thyroxine in the young male rabbit ${ }^{3}$, their effects on the adrenals were also studied.

The results of the present experiments indicated that the level of thyroidal stimulation determines to some extent the size of the adrenals in the male rabbit. Administration of thyroxine in doses about $30-50$ per cent above the estimated rate of secretion of thyroxine, for a period of four weeks, resulted in a significant increase in the weight of the adrenals, while treatment with thiouracil caused a significant decrease in the male rabbit. Thyroxine, when injected in doses below or about equal to the estimated rate of secretion of thyroxine, did not affect the weight of the adrenals. On the other hand, severe hyperthyroidism resulted in a significant decrease in the weight of the adrenals. The results of the experiments with the male mouse ${ }^{4,5}$ and the rabbit suggest that there may exist an interrelationship between the thyroid, adrenals and gonads.

Castration did not affect the weight of the adrenals of 8-week old male rabbits after a period of four weeks, but resulted in a significant increase in the weight of the adrenals after a period of twenty-four weeks. During the summer months there occurred a significant decrease in the weight of the adrenals when compared with the winter values. Detailed results will be described elsewhere.

I am indebted to Dr. J. Hammond and Dr. Arthur Walton for their interest during the course of the present work, and to Mr. A. G. Carruthers for statistical analysis of the results.

School of Agriculture,

University of Cambridge.

$$
\text { Oct. } 22 .
$$

'Maqsood, M., Experientia (in the press).

${ }^{2}$ Maqsood, M., Nature $[168,692(1950)]$.

3 Maqsood, M., Nature [168, 735 (1950)].

-Maqsood, M., and Reineke, E. P., Amer. J. Physiol., 162, 24 (1950).

${ }^{5}$ Maqsood, M., J. Endocrinol., 7, 82 (1950).

\section{A Staining Technique for the Study of Temperature-Shock in Semen}

Lasley, Easley and McKenzie ${ }^{1}$ have shown that the increased staining propensity of dead cells may be used to obtain a quantitative estimate of the proportions of live and dead spermatozoa in freshly ejaculated ram semen, and have described a technique of staining with Opal Blue and Eosin which employs this principle. They have also emphasized that the imposition of temperature-shock on test ejaculates by sudden cooling is accompanied by an increase in the proportion of stained spermatozoa. In their studies, shock effects due to differences of temperature between semen and stain at the time of mixing were rigidly excluded, and no subsequent attempt has apparently been made to determine the critical level at which such temperature effects may be encountered, or to express in quantitative terms the degree of shock encountered at different temperature-levels.

Field experience with a similar technique developed in this laboratory suggested an investigation of this point. The staining solution used was prepared by dissolving $5 \mathrm{gm}$. water-soluble Eosin $Y$ (Gurr) in $300 \mathrm{ml} .10$ per cent aqueous Nigrosin (Gurr). Samples of fresh bull semen held at a temperature of $30^{\circ} \mathrm{C}$. were stained for five minutes by dilution with this solution at a series of temperature-levels over the range $0^{\circ}-30^{\circ} \mathrm{C}$., and the number of stained spermatozoa was determined microscopically from duplicate smears of each suspension.

Analysis of the results obtained from a study of six bulls shows that the proportion of stained spermatozoa increases with the temperature-difference between semen and stain. This relationship is expressed graphically in the accompanying figure, and illustrates the findings on a single ejaculate from one of six bulls studied. The mean percentage of dead spermatozoa

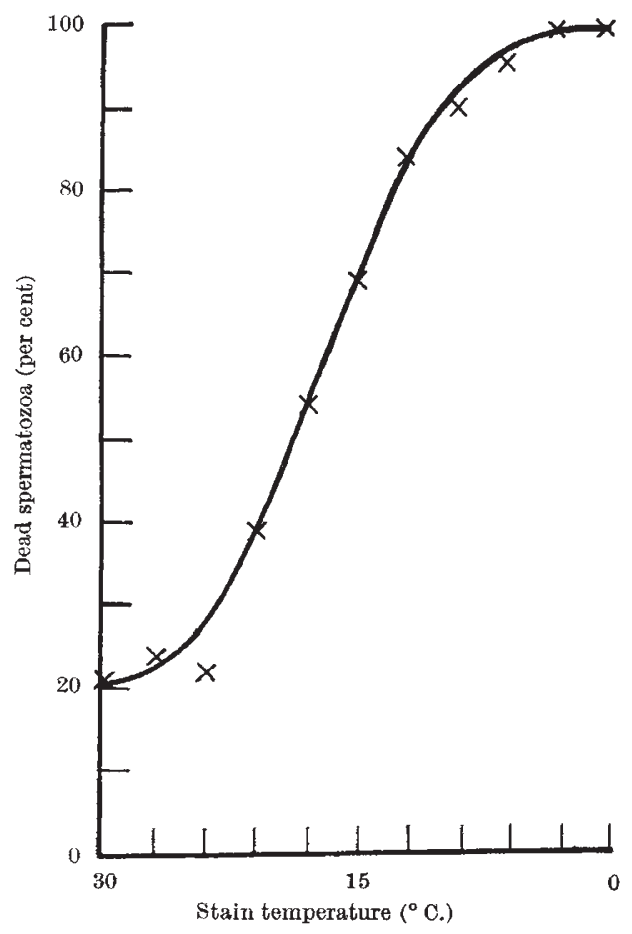

Effect of varying degrees of temperature shock on the staining affinity of bull spermatozoa 